\title{
An Investigation of the Effectiveness of Vocabulary Learning Strategies on Iranian EFL Learners' Vocabulary Test Score
}

\author{
Ramin Rahimy ${ }^{1} \&$ Kiana Shams ${ }^{1}$ \\ ${ }^{1}$ Department of English language, Islamic Azad University-Tonekabon Branch, Tonekabon, Iran \\ Correspondence: Kiana Shams, Department of English Language, Islamic Azad University-Tonekabon Branch, \\ Tonekabon, Iran. Tel: 98-911-338-7309. E-mail: kiana.shams@gmail.com
}

Received: May 10, 2012

Accepted: May 22, 2012 Online Published: August 23, 2012

doi:10.5539/ies.v5n5p141

URL: http://dx.doi.org/10.5539/ies.v5n5p141

\begin{abstract}
This study aims to investigate the effectiveness of vocabulary learning strategies on Iranian EFL learners' vocabulary test score. To achieve this aim, fifty Intermediate level students from Kish English Institute were randomly selected from among fifteen classes after administering the Oxford Placement Test (OPT). Then, an intermediate level vocabulary test of 20 questions based on their class textbook named Total English was given to them. A questionnaire of vocabulary learning strategies (VLSQ) was, then, distributed among students to find out how each learner learned new vocabulary and in what way. Finally, the whole data gathered from OPT; vocabulary test and VLSQ were analyzed through SPSS by applying Chi-square and descriptive analysis. The findings showed a significant effect of vocabulary learning strategies on EFL learners' performance in a vocabulary test.
\end{abstract}

Keywords: vocabulary, vocabulary learning, VLSs, VLSQ

\section{Introduction}

Vocabulary learning strategies mostly called VLSs are among significant issues in English language learning which have been taken into consideration during previous decades. EFl/ESL learners have always complained about forgetting whatever vocabularies they have memorized. In order to suggest solutions to this problem or even present some useful guidelines to both learners and teachers in this regard, many studies have been made in the field of Vocabulary Learning (VL). There are numbers of strategies which are used by students to learn new vocabulary items, however, they seem to lack the distinguishing criteria about which strategy to choose and which one to exclude.

"Vocabulary learning is referred to as learning a collection or the total stock of words in a language that are used in particular contexts" as Siriwan (2007) holds. Siriwan (2007: 19) believes that vocabulary learning means learning a package of sub-sets of words as well as learning how to use strategies to cope with unknown or unfamiliar words. Vocabulary learning strategies refer to "any set of techniques or learning behaviors, which language learners use to understand the meaning of a new word, to restore the knowledge of newly-learned words, and to expand one's knowledge of vocabulary" (Intaraprasert, 2004: 53). When language learners encounter a new word, they usually recognize it, but might not be able to use it later on. After a while, when they use the word in their speaking or writing, it becomes their active vocabulary (Baker and Westrup 2000, as cited in Siriwan, 2007). All students use VLSs in some way, but most of them are not aware of these strategies and they do not know which strategies they are applying. Language learners require a great deal of effort in order to learn new words when they occur, and be successful and independent learners (Miller and Gildea, 1987; Nation, 1990 as cited in Siriwan, 2007).

Siriwan (2007), quoting from Harmer (1991) and Schmitt (1997), asserts that introducing language learners to great number of strategies can be very helpful since they can select the individual strategies that suit their individual learning styles. As language learners might not choose correct strategies and as they learn words in a variety of ways, thus, teaching various VLSs can help them to be successful and independent language learners (Cameron 2001: 93 as cited in Siriwan, 2007). Studies made recently in second language vocabulary learning (Brown and Perry, 1991; Sanaoui, 1995; Schmitt, 1997; Stoffer, 1995 as cited in Siriwan, 2007) revealed that particular VLSs were more effective in learning new vocabulary items. 
Cameron (2001: 92) defines VLSs as "the actions that learners take to help themselves understand and remember vocabulary items". Catalan (2003: 56) adopts the definition of vocabulary learning strategies from Rubin (1987); Wenden (1987); Oxford (1990); and Schmitt (1997) as the working definition in her study as "knowledge about the mechanisms (processes, strategies) used in order to learn vocabulary as well as steps or actions taken by students (a) to find out the meaning of unknown words, (b) to retain them in long-term memory, (c) to recall them at will, and (d) to use them in oral or written mode". Similarly, Intaraprasert (2004: 9) has defined vocabulary learning strategies as "any set of techniques or learning behaviors, which language learners reported using in order to discover the meaning of a new word, to retain the knowledge of newly-learned words, and to expand their knowledge of vocabulary.'(As cited in Siriwan, 2007)

\subsection{VLSs Classifications}

There have been many different classifications of vocabulary learning strategies given by various scholars. The following classifications are extracted from Siriwan (2007).

The strategy inventory offered by Schmitt (1997) is presented below:

Category 1: Strategies for the discovery of a new word's meaning

- Determination Strategies (DET)

- Analyze part of speech;

- Analyze affixes and roots;

- Check for L1 cognate;

- Analyze any available pictures or gestures;

- Guess meaning from textual context;

- Use a dictionary (bilingual or monolingual)

- Social Strategies

- Ask teacher for a synonym, paraphrase, or L1 translation of new word;

- Ask classmate for meaning

Category 2: Strategies for consolidating a word once it has been encountered

- Social Strategies

- Study and practice meaning in a group;

- Interact with native speaker

- Memory Strategies

- Connect word to a previous personal experience;

- Associate the word with its coordinates;

- Connect the word in its synonyms and antonyms;

- Use semantic maps;

- Image word form;

- Image word's meaning;

- Use Keyword Method;

- Group words together to study them;

- Study the spelling of a word;

- Say new word aloud when studying;

- Use physical action when learning a word

- Cognitive Strategies

- Verbal repetition;

- Written repetition;

- Word lists;

- Put English labels on physical objects; 
- Keep a vocabulary notebook

- Metacognitive strategies

- Use English-language media (songs, movies, newscasts, etc.);

- Test oneself with word tests;

- Skip or pass new word;

- Continue to study word over time

VLSs are grouped under three main categories by Cohen $(1987 ; 1990)$ :

-Strategies for Remembering Words

-Using Rote-repetition;

-Using Mnemonic Associations;

-Semantic Strategies;

-Vocabulary Learning and Practicing Strategies

Strategies for dealing with vocabulary items proposed by Cohen $(1987 ; 1990)$ include strategies for remembering words, semantic strategies, and vocabulary learning and practicing strategies.

Rubin and Thompson (1994: 79-82) introduced three main categories of VLSs and their sub-categories including:

-Direct Approach

-Put the words and their definitions on individual cards;

-Say the words aloud or write them over and over again as they study;

-Compose sentences with the words they are studying;

-Tape records the words and their definition, if they prefer to learn through the ear;

-Color-code words by parts of speech, if they prefer to learn through the eye

-Use Mnemonics

-Use rhyming;

-Use alliteration;

-Associate words with the physical world;

-Associate words with their functions;

-Use natural word associations, such as opposites;

-Learn classes of words;

-Learn related words;

-Group words by grammatical class;

-Associate words with context

-Indirect Approach

-Read a series of texts on a related topic;

-Guess the meaning of words from context; and

-Break up the word into components

Stoffer (1995) clustered VLSs into 9 categories:

1. Strategies involving authentic language use;

2. Strategies used for self-motivation;

3. Strategies used to organize words;

4. Strategies used to create mental linkages;

5. Memory strategies;

6. Strategies involving creative activities; 
7. Strategies involving physical action;

8. Strategies used to overcome anxiety;

9. Visual/auditory strategies

What follow is vocabulary learning strategies classified by Gu and Johnson (1996):

-Beliefs about vocabulary learning;

-Metacognitive regulation;

-Guessing strategies;

-Dictionary strategies;

-Note-taking strategies;

-Memory strategies (rehearsal);

-Memory strategies (encoding);

-Activation strategies

The individual vocabulary learning strategies are classified under four different categories by Lawson and Hogben (1996: 118-119):

-Repetition

-Reading of related word;

-Simple rehearsal;

-Writing of word and meaning;

-Cumulative rehearsal;

-Testing

-Word Feature Analysis

-Spelling;

-Word classification;

-Suffix

-Simple Elaboration

-Sentence translation;

- Simple use of context;

-Appearance similarity;

-Sound link

Complex Elaboration

-Complex use of context;

-Paraphrase;

-Mnemonic

\section{Purpose and Significance of the Study}

For both groups of EFL / ESL learners learning new words and memorizing a lot of vocabularies in order to use them later on have been problematic at all times. Learners try many ways and use many different vocabulary learning strategies. Nobody can memorize all the words in any language, and learning all English vocabularies is something that even native speakers never master, but learners should know which strategy is suitable to them, can lead them to a better understanding and learning in a shorter time and can help them learn as many useful words as possible. The results of different studies made by different scholars on vocabulary learning strategies revealed that VLSs, reported as being applied by participants, such as keyword method, dictionary use have been effective and beneficial while learning new vocabulary items as shown in Brown and Perry's research work (1991), in Luppescu and Day's study (1993).

What follow are the available research works on vocabulary learning strategies conducted in other countries that are extracted from Siriwan (2007). The outcome of Taichi's study (2000) showed that there were gender 
differences in dictionary use, note-taking and repetition strategies. The year variable was found related to dictionary use, note-taking and repetition strategies. The location in which the Japanese students learn was found to be the most significant factor affecting all aspects of VLS use.

Winke did a research with the overall VLS use as the focus of the study in 2001. The results of this research revealed 1) Students used both non-negotiating (direct) and negotiating (indirect) strategies for acquiring Chinese as a foreign language. They modeled and repeated words memorized words and wrote words by taking notes in class and by practicing words at home. 2) Most class time was spent in the teacher modeling and the students repeating, or with the students being called on one by one. Neither group works nor discussions amongst themselves in Chinese outside of the normal greetings of the day were practiced.

The outcome of Gallo-Grail \& Zerwekh's study (2002) showed that 1) Students used both non-negotiating (direct) and negotiating (indirect) strategies for acquiring Chinese as a foreign language. They modeled and repeated words memorized words and wrote words by taking notes in class and by practicing words at home. 2) Most class time was spent in the teacher modeling and the students repeating, or with the students being called on one by one. Neither group works nor discussions amongst themselves in Chinese outside of the normal greetings of the day were practiced.

Catalan (2003) found out that Males and females differ significantly in the number of strategies used. Regarding the range of vocabulary learning strategies, eight out of ten most frequent strategies are shared by males and females. Differences of total vocabulary learning strategies were reported using between males and females. Marefat \& Shirazi (2003) indicated that learners strategy use in short-term retention far outweighs that in long-term retention. Memory strategy use was portrayed both in short and long-term retention. The next most frequently used strategies were cognitive and compensation strategies respectively.The study by Rasekh \& Ranjbry (2003) revealed that explicit metacognitive strategy training has a significant positive effect on the vocabulary learning of EFL students.

The present study has been done in order to provide both teachers and learners with comprehensive and thorough knowledge about vocabulary learning strategies as much as possible and it attempts to investigate whether the results obtained will confirm the finding of previous studies in language learning settings. VLSs included in the VLSQ of the present study are grouped under five categories of cognitive, memory, metacognitive, determination and social strategies classified by Schmitt (1997). The present investigation aims to investigate the effect of these VLSs on English learners learning new words. Specifically, the purposes of the present investigation are: 1. to investigate types and frequency of vocabulary learning strategies which Iranian EFL learners apply to discover the meaning of new vocabulary items, to retain the knowledge of the newly-learned vocabulary items, and to expand the knowledge of vocabulary; 2. to investigate the relationships between the types of vocabulary learning strategies students use and their vocabulary test score.

Students who are learning English as a foreign language in Iran have always encountered this problem that they cannot restore and retain the vocabulary items that they learn. So being aware of VLSs can make learning new vocabularies much easier for them. As is quite impossible for Persian EFL learners to communicate with native speakers outside English learning institutes, they should know how to use an effective VLS inside the classrooms in order to improve their communication abilities and use this opportunity to apply what they learn. Some students give up learning English as soon as they encounter harder words in higher levels and do not like to continue and think that English is a difficult language to learn and lose their interest. So Language teachers in English institutes or schools may be able to make use of findings of the present study to improve their vocabulary teaching techniques and they can be able to change the misunderstanding about vocabulary learning of their students.

This study is significant and beneficial both for teachers and learners because it will eliminate misunderstanding of learning English. Teachers may be able to provide more interesting condition and a better classroom atmosphere by informing learners with various applicable VLSs and try to make students believe that learning English is so much interesting and enjoyable. Therefore students may get better results in their vocabulary tests. Many researchers believe that if the EFL/ESL learners know about VLS, they can work on one or two special strategies that are more applicable for them so that they can learn better and develop their vocabulary learning. Rasekh and Ranjbary (2003) found out in their research that explicit metacognitive strategy training has a significant positive effect on the vocabulary learning of EFL students. Therefore, hoping to solve this problem, this study intends to investigate how one learner can improve his/her vocabulary learning and also his/her language learning by giving them enough information about various VLS that exist and inform them which strategy is more practical for them. The present investigation aims to investigate the effect of VLS on English 
learners learning new words. This should be indicated that the focus is on learning not merely memorizing vocabularies. Memorization does not necessarily lead to learning. When something is learned properly, it is unlikely it will ever be forgotten. It will be restored in long-term memory.

\section{Research Question and Hypothesis of the Study}

Based on the problems and purpose discussed above, the following research question was addressed:

Does VLSs affect Intermediate Iranian EFL learners' vocabulary test score?

Based on the above research question, the following null hypothesis is formulated:

VLSs do not affect Intermediate Iranian EFL learners' vocabulary test score.

\section{Definitions of Key Terms}

\subsection{Vocabulary}

Richards et al. (1992) has defined this term as a set of lexemes which includes single words, compound words and idioms.

\subsection{Vocabulary Learning}

Learning a package of sub-sets of words as well as learning how to use strategies to cope with unknown or unfamiliar words.

\subsection{VLSs (Vocabulary Learning Strategies)}

The term "vocabulary learning strategies" refers to "any set of techniques or learning behaviors, which language learners use to understand the meaning of a new word, to restore the knowledge of newly-learned words, and to expand one's knowledge of vocabulary" (Intaraprasert 2004, as cited in Siriwan, 2007).

\subsection{VLSQ (Vocabulary Learning Strategy Questionnaire)}

Vocabulary learning strategy questionnaire comprises some question items including Vocabulary learning strategies. There may be various VLSs categories included in questions with some of their subcategories. Each item may come with three or choices or options to choose which are mainly never, rarely, often and always or agree, strongly agree, disagree, strongly disagree.

\section{Method}

\subsection{The Design of the Study}

Sixty four EFL learners majoring in different fields at Kish English Language Institute, Rasht branch, Iran took part in the study. Following an Oxford Placement Test (OPT), intermediate level learners were selected for the study. This test was used to enable the researcher to select a homogeneous group. After correcting the papers, 50 students were selected as the Intermediate group based on the OPT manual (Those participants whose grades were among 12 to 22 (total grades $=30$ ) were selected). Afterwards, a vocabulary test of 20 multiple-choice questions was given to them. The vocabulary test was provided to the learners based on their class book named Total English at the Intermediate level. Then a questionnaire of 30 items with questions referring to various vocabulary learning strategies was distributed among students. Finally, the whole data gathered from OPT; vocabulary test and the questionnaire were analyzed through SPSS by applying Chi-square and descriptive analysis.

\subsection{Participants}

In the present study, all of the sixty participants were female with the age range of 20_30. They were EFL learners learning English in a classroom setting. The initial number of learners was reduced to fifty after the administration of OPT. They were all intermediate level EFL learners from Kish English language Institute, Rasht branch, Iran. The participants were all female; majoring in different fields at different universities in Iran.

\subsection{Materials}

To conduct the present study, three instruments were employed.

They were as follows:

1. Oxford Placement Test (OPT)

2. A vocabulary test at the Intermediate level

3. A Vocabulary learning strategies questionnaire (VLSQ) 
The scores of the participants on OPT were used to measure the vocabulary knowledge of the participants. Each subtest, i.e. cloze-passage and vocabulary items, contained 30 items in multiple-choice format. Only two parts of this test were chosen including 60 questions of vocabulary test items and Cloze-passage. The allotted time for answering the questions was 45 minutes. The vocabulary test was based on the words extracted from students' class book and their final exams whose reliability, evaluated through KR-21, was 0.6. It included 20 questions and one score was allotted for each item.

In the present study the VLSQ used in order to see how each learner learn new vocabularies and in what way. It was revised from two different vocabulary learning questionnaires. One of the VLSQs was edited by Ming Wie (2007) which had previously been adapted from Gu and Johnson (1996) and Fan (2003) and was done in Oklahoma State University of USA and the other one is a questionnaire done in Georgetown University Center for Applied Linguistics in The George Washington University [Online] Available: national capital language resource center. To avoid any misunderstanding, the translated version of VLSQ was used. The inter-rater reliability of this questionnaire was confirmed by 6 professors. The VLSQ include five categories of cognitive, memory, metacognitive, determination and social strategies with some questions referring to their subcategories. There were 4 choices for each question which were never, rarely, often and always.

\subsection{Procedures}

To achieve the purpose of the study, the following procedures were followed in three sessions. The analyses of the scores of OPT indicated that 12 of the participants had to be excluded from the study due to a different proficiency level. Following an Oxford Placement Test (OPT), a multiple-choice vocabulary test based on students' class book and their archived final exams was given to the participants. At the final session, a vocabulary learning strategy questionnaire was administered. Having administered the tests and the questionnaire and gathered the data, in order to answer the research question, in SPSS, chi-square was run to find out the effect of VLSs on intermediate EFL learners' test score. And also two descriptive analyses are done on OPT and on Vocabulary test scores of all participants.

\section{Results and Discussion}

The research question attempted to find the effect of VLSs on Intermediate Iranian EFL learners' vocabulary test score. To this end, chi-square was used. Tables 1 to 30 summarize non-parametric statistics for the VLS questionnaire with one table for each question. Some of the questions in the VLSQ belonged to one category of VLSs and some other to another category or subcategory. There are four options to choose that are as never, rarely, often and always. Never and rarely are considered as negative options and often and always as positive ones.

\subsection{The Explanation of Vocabulary Test Scores}

The information about vocabulary test scores of participants was analyzed through descriptive statistics in SPSS software. All the learners are classified in two groups on the basis of their vocabulary test results, 35 participants who have got the score between 15 and 20 belong to high-score group and 15 students who have got the score between 9 and 14 belong to low-score group. (See table1)

Table 1. Vocabulary test scores: Descriptive statistics

\begin{tabular}{llllll}
\hline & $\mathrm{N}$ & Minimum & Maximum & Mean & \multicolumn{1}{c}{ Std. Deviation } \\
\hline Score & 50 & 9.00 & 20.00 & 15.6000 & 2.81396 \\
Valid N (listwise) & 50 & & & & \\
\hline
\end{tabular}

As shown in Table 1, Vocabulary test total score is 20. Minimum score is 9 and maximum is 20.the mean of scores is 15.6 and standard deviation is about 2.81 .

\subsection{The Explanation of Percentages of Negative and Positive Answers for VLSQ}

The information related to percentage of all VLSs categories, included in questionnaire and shown in Table2, illustrates details about the percentage of students' answers in both groups choosing one of positive or negative options in all questions. Five different categories of VLSs were included in the questionnaire that some of the questions referred to each of the VLSs category as are shown in this table. The percentages of negative and 
positive answers for each strategy for both high-score and low-score groups are presented in two last columns in the table. (See table2)

Table 2. Percentage of Negative and Positive answers for VLSs

\begin{tabular}{|c|c|c|c|c|c|}
\hline \multirow{3}{*}{$\begin{array}{l}\begin{array}{l}\text { Category of } \\
\text { strategies }\end{array} \\
\text { Cognitive strategy }\end{array}$} & \multirow{3}{*}{$\begin{array}{l}\text { Question items } \\
13,14,15,18,29 \text { and } 30\end{array}$} & \multicolumn{2}{|c|}{$\begin{array}{l}\text { Percentage of } \\
\text { Never and rarely (\%) }\end{array}$} & \multicolumn{2}{|c|}{$\begin{array}{l}\text { Percentage of } \\
\text { Often and always (\%) }\end{array}$} \\
\hline & & L-score & 72.22 & L-score & 27.77 \\
\hline & & H-score & 50.95 & H-score & 49.04 \\
\hline \multirow{2}{*}{ Memory strategy } & \multirow{2}{*}{$1,2,4,5,12,19,20$ and 26} & L-score & 55 & L-score & 45 \\
\hline & & H-score & 45.35 & H-score & 54.64 \\
\hline \multirow{2}{*}{$\begin{array}{l}\text { Metacognitive } \\
\text { strategy }\end{array}$} & \multirow{2}{*}{$10,11,21,27$ and 28} & L-score & 33.33 & L-score & 66.33 \\
\hline & & H-score & 53.71 & H-score & 46.28 \\
\hline \multirow{2}{*}{$\begin{array}{l}\text { Determination } \\
\text { strategy }\end{array}$} & \multirow{2}{*}{$7,8,16,17,22,23,24$ and 25} & L-score & 35 & L-score & 65 \\
\hline & & H-score & 28.21 & H-score & 71.78 \\
\hline \multirow{2}{*}{ Social strategy } & \multirow{2}{*}{3 and 9} & L-score & 76.66 & L-score & 23.33 \\
\hline & & H-score & 85.71 & H-score & 14.28 \\
\hline
\end{tabular}

The results showed that High-score students' VLS overall use is somehow more than that of their counterparts. The percentages show that low-score group chose positive answers, i.e. often and always, less than High-score group. This means that they do not try different ways for vocabulary learning if one ways does not work. The most frequently used VLSs by the students in High-score group were cognitive, memory and determination strategies. The metacognitive and social strategies were strategies used least often. Each VLS category got three or more subcategories that each question item referred to. For example question 1 which belonged to memory strategy referred to Using Keyword Method and question number 13 included in cognitive strategy category mentioned written repetition strategy and so on.

Questions number 13,14, 15, 18, 29 and 30 belonged to the first category (i.e. cognitive strategy). The percentage of negative answers for this category was 72.22 for L-score group and 50.95 for H-score group. The percentage of positive answers for cognitive strategy, along with its subcategories, was 27.77 for L-score group and 49.04 for H-score group. This indicates that active learners tended to apply one kind of cognitive strategies now and then in different situations.

Questions number 1,2,4,5,12,19,20 and 26 belonged to memory strategy category. The percentage of negative answers for this category was 55 for L-score group and 45.35 for H-score group. The percentage of positive answers for memory strategy was 45 for L-score group and 54.64 for H-score group.

Metacognitive strategy including questions number 10, 11, 21, 27 and 28 was the third category. The percentage of negative answers for this category was 33.33 for L-score group and 53.71 for H-score group. The percentage of positive answers for metacognitive strategy was 66.33 for L-score group and 46.28 for H-score group. This result indicates that students with higher score in vocabulary test did not often or always use one of the metacognitive strategies such as Testing oneself with word tests, Using English-language media (songs, movies, newscasts, etc.) and Continuing to study word over time (Schmitt categorization 1977). Weaker students seemed to use these strategies more and tried to check their vocabulary knowledge occasionally. This perhaps made them feel nervous and stressful or made them reluctant and bored in learning new words, because of that their vocabulary knowledge did not improve a lot.

Determination strategy the fourth taxonomy included questions 7, 16, 17,22,23,24 and 25 in which the percentage of negative answers was 35 for L-score group and 28.21 for H-score group. The percentage of positive answers was 65 for L-score group and 71.78 for H-score group.

Questions 3,8 and 9 are the only questions included in Social strategy taxonomy. The percentage of negative answers was 76.66 for L-score group and 85.71 for H-score group. The percentage of positive answers was 23.33 for L-score group and 14.28 for H-score group. Students who were better at vocabulary learning chose negative options more than their counterparts that shows the weaker vocabulary learners usually tend to use one of social 
strategies. For instance, as they have answered in the questionnaire, low-score group preferred to ask teacher for a synonym, paraphrase, or L1 translation of new word and they tended to Study and practice in peer groups. These students liked to ask Persian translations of new words they encounter of their teachers or other classmates to get to the vocabulary's meaning sooner. They do not like to guess or find the meaning of the words by themselves.

\section{Conclusion}

On the basis of the results gathered from vocabulary test and VLSs questionnaire, it can be said that the hypothesis of the present study saying VLSs do not affect Intermediate Iranian EFL learners' vocabulary test score is rejected as most of the high-score students have often or always applied the strategies given in the questionnaire in order to improve their vocabulary knowledge. To make it more tangible why the hypothesis is rejected a short summary of whole results is presented in the following paragraphs.

As it is clear in table 32, the percentages of negative answers for the strategy categories were 72.22, 55, 33.33, 35, and 76.66 for L-score group in order brought in the table. Those of H-score group were 50.95, 45.35, 53.71, 28.21 and 85.71. These results show that metacognitive and social strategies were those strategies used least often by students in H-score group. The percentages of positive answers for L-score group were 27.77, 45, 66.33,65 and 23.33. Those of H-score group were 49.04, 54.64, 46.28, 71.78 and 14.28. These outcomes shows that EFL learners in H-score tended to apply various kinds of cognitive, memory and determination strategies in learning new vocabularies, therefore they could get higher scores in the vocabulary test. Those who got lower scores in vocabulary test seem not to use these strategies a lot and that is the problem which should be eliminated as much as possible. Suggesting those strategies reported being applied by High-score group to those in weaker group, can help Low-score group and other EFL learners with similar conditions to improve their vocabulary learning and get higher scores in their final exams and also in vocabulary tests.

\section{References}

Baker, J., \& Westrup, H. (2000). The English language teacher's handbook: How to teach large classes with few resources. London: Continuum.

Brown, T. S., \& Perry, F. L. Jr. (1991). A comparison of three learning strategies for ESL vocabulary acquisition. TESOL Quarterly, 25(4), 655-670.

Cameron, L. (2001). Teaching languages to young learners. Cambridge: Cambridge University Press. Retrieved from http://cambridge.org/9780521774345

Catalan, R. M. J. (2003). Sex differences in L2 vocabulary learning strategies. International Journal of Applied Linguistics, 13(1), 54-77.

Cohen, A. D. (1987). The use of verbal and imagery mnemonics in second language vocabulary learning. Studies in Second Language Acquisition, 9, 43-62.

Cohen, A. D. (1990). Language learning: Insights for learners, teachers, and researchers, Boston, Mass.: Heinle and Heinle Publishers.

Fan, M.Y. (2003). Frequency of use, perceived usefulness, and actual usefulness of second language vocabulary strategies: A study of Hong Kong learners. Modern Language Journal, 87(2), 222-241.

Gallo-Crail, R., \& Zerwekh, R. (2002). Language learning and the internet: Student strategies in vocabulary acquisition. In C.A. Spreen (ed.), New technologies and language learning: Cases in the less commonly taught languages technical report \#25. Honolulu, HI: University of Hawaii, Second language teaching and curriculum centre (pp. 55-79). Retrieved from http://nflrc. hawaii.edu/ networks/tr25/TR25-3.pdf

Gu, P.Y., \& Johnson, R. K. (1996). Vocabulary learning strategies and language learning outcomes. Language Learning, 46(4), 643-679.

Harmer, J. (1991). The practice of English language teaching. London: Longman.

Hedge, T. (2000). Teaching and learning in the language classroom. Oxford: Oxford University Press.

Intaraprasert, C. (2004). EST students and vocabulary learning strategies: A preliminary investigation. Unpublished research, Suranaree University of Technology, Nakhon Ratchasima, Thailand.

Lawson, M. J., \& Hogben, D. (1996). The vocabulary-learning strategies of foreign-language students. Language Learning, 46(1), 101-135. 
Luppescu, S., \& Day, R. R. (1993). Reading, dictionaries, and vocabulary learning. Language Learning, 43(2), 263-287.

Marefat, H. (2003). The impact of teaching direct learning strategies on the retention of vocabulary by EFL learners. The Reading Matrix, 3(2), 47-62.

Miller, K. E., \& Gildea, D. (1987). The foreign language syllabus and communicative approaches to teaching: Special issue of studies in second language acquisition. Oxford: Oxford University Press.

Nation, P. (1990). Teaching and learning vocabulary. Boston: Heinle \& Heinle.

Nation, P. (2001). Learning vocabulary in another language. Cambridge: Cambridge University Press.

Oxford, R. (1990). Language learning strategies: What every teacher should know. New York: Newbury House.

Rasekh, Z. E., \& Ranjbary, R. (2003). Metacognitive strategy training for vocabulary learning. Teaching English as a Second or Foreign Language, 7(2), 1-21.

Rubin, D. (1987). Learner strategies: Theoretical assumptions, research, history, and typology. In A. Wenden and J. Rubin (Eds.), Learner strategies in language learning (pp. 15-30). Eaglewood Cliffs, New Jersey: Prentice-Hall.

Rubin, J., \& Thompson, I. (1994). How to be a more successful language learner: Toward learner autonomy (2nd ed.). Boston, MA: Heinle \& Heinle.

Sannoui, R. (1992). Vocabulary Learning and Teaching in French as a Second Language Classrooms, Unpublished doctoral diss., University of Toronto, Toronto, Ontario, Canada.

Schmitt, N. (1997). Personal communication, $31^{\text {st }}$ IATEFL Conference, 2-5 April 1997, Brighton, UK.

Schmitt, N. (1997). Vocabulary learning strategies. In N. Schmitt and M. McCarthy (Eds.), Vocabulary: Description, acquisition and pedagogy (pp. 77-85). Cambridge: Cambridge University Press.

Schmitt, N., Bird, R. Tseng, A., \& Yang, Y.C. (1997). 'Vocabulary lerning strategies: Student perspectives and cultural considerations.' Independence Spring, 4-6.

Siriwan, M. (2007). English vocabulary learning strategies employed. Rajabhat university students: Unpublished Doctoral Dissertation, the University of Suranaree, Malaysia. Retrieved from http://sutir.sut.ac.th:8080/sutir/bitstream/123456789/284/1/mayuree_fulltext.pdf

Stoffer, I. (1995). University foreign language students' choice of vocabulary learning strategies as related to individual difference variables. Unpublished Doctoral Dissertation, the University of Alabama, USA.

Taichi, N. (2000). The use of vocabulary learning strategies: The case of Japanese EFL learners in two different learning environments. Unpublished Doctoral Dissertation, University of Essex, UK.

Vocabulary Learning Strategies Questionnaire. (1994). NCLRC Georgetown University. Center for Applied Linguistics, the George Washington University. Retrieved from http://nclrc.org/teaching_materials/assessment/nclrc_assessment_tools. ml

Wei, M. (2007). An Examination of Vocabulary Learning of College-level Learners of English in China, Oklahoma State University, Stillwater, Oklahoma, USA. The Asian EFL Journal Quarterly, 9(2). Retrieved from http://www.asian-efl-journal.com/June_2007_EBook_editions.pdf

Wenden, A. (1987). Conceptual background and utility. In A. Wenden and J. Rubin (Eds.), Learner strategies in language learning (pp. 3-13). London: Prentice Hall International.

Winke, P. (2001). Strategies for vocabulary acquisition in a Chinese as a foreign language classroom. Retrieved from http://epsilon3.georgetown.edu/ pmw2/ppers/ QP1.html

\section{Appendix}

Appendix 1.Vocabulary Test

1. It's against the law, isn't it? Oh, yes, it's

. a) Irregular b) illegible

c) illegal

d) impossible

2. His room is always in a mess, isn't it? Yes, it's very . a) Invisible b) clean

c) unusual

d) untidy

3. She's terrible sometimes. Yes, she can be very a) Informal

b) honest

c) unpleasant

d) polite

4. We

d) depart as soon as we got to the hotel. Then we can go for a walk. a)Untidy

5. I lost the bus because I

a) Overcharged

b) overdone

c) overslept

d) overload 
6. After finding the last victim's body, police arrested that cruel a)Operator

b) director c)murderer d) mentalist

7. David is working in a magazine, he is a good journalist
a) Explorer
b) jogger
c) expert
d)
8. We to the waiter about the terrible food. a) Nag
b) complained
c) fought
d) suggested
9. I can't a phone call, I'm so angry now. a) Do
b) try
c) give
d) make

10. I think you're right. I with you. a) Agree

b) contemplate

c) thought

d) appreciate

11. it's really , I can't stop laughing. a) Brilliant

b) ridiculous

12. His books are amazing; I'm really in them. a) Liked

b) prefer

c) unpleasant

d) disgusting

13. Sara called and said she can't come to the party. Oh, . a)What a mess

c) pleased

d) interested what a pity d) that sounds dreadful

14. I couldn't the bus yesterday. a) Catch

b) give

c) leave

b) that's not fair

c)

15. It was very ,I enjoyed your performance. a) Awful

b) tolerable

c) brilliant

d) lose

16. She for this job, I'm sure she does her best. a)Look

b) gain

c) qualify

d) wondering

17. My mother always me about marriage. a) Accomplish

b) prevent

c) advise

d) fight

18. one of my colleagues has been . she's so happy now. a) Tempted d) promoted

19. Giving one thing in return for another refers to the word d) exhale . a) Recruit

b) revised

d) tease

20. Jack buy a lot of jeans and t-shirts, he's really
a) Extravagant
b) jealous
c) eager
d) disgraceful

\section{Appendix.2 QUESTIONAIRE OF VOCABULARY LEARNING STRATEGIES}

1. As I think about an English word, I imagine or draw a picture of the object/idea the word represents.

2. I think of something or someone in my life that the word reminds me of, and I remember that connection when I need to recall the word.

3. I ask the teacher for Persian translation.

4. I group words that are similar or are related in some way.

5. I hold or point to an object that the English word represents while thinking or saying the word.

6. I think of a Persian word that looks or sounds like the English word, and I think about how the meanings are related.

7. I look for structural rules (prefixes, suffixes, roots, etc.) that give clues to the word's meaning.

8. I guess the meaning of the word from the textual context in reading.

9. I review new words with a classmate.

10. I test myself to see if I have learned the words.

11. I use English-language songs in order to learn new words.

12. I connect the word to its synonyms and antonyms.

13. I use new words in sentences.

14. I repeat a new word out loud several times to remember it.

15. I learn new words by writing it over and over.

16. I carry a pocket dictionary (including an electronic dictionary) to look up the words I don't know.

17. I pay attention to the grammatical patterns (e.g. parts of speech, countable/uncountable) of a new word.

18. I keep a vocabulary notebook.

19. I associate new words with those I already know.

20. I make word cards. 
21. I highlight the words that seem important to me.

22. When I look up a word in the dictionary, I read all the meanings of new words.

23. I check to see if my guesses about the words are right or wrong.

24. I look up new words in an English-Persian dictionary.

25. I try to remember the Persian equivalent of the word.

26. I imagine the word's meaning.

27. I listen to English songs, radio programs, watch English movies etc. to increase my vocabulary.

28. Read stories, magazines etc. outside class to increase my vocabulary.

29. I use the newly-learned words as much as possible in speaking and writing.

30. I make a list of new words to memorize. 